\title{
A method for approximating the CHF of subcooled flow boiling in microgravity by ground tests
}

\author{
Bin Liu a , Bo Yuan ${ }^{a}$, Pengzhuo Xu ${ }^{a}$, Jianfu Zhao ${ }^{\mathrm{b}, \mathrm{c}}$, Yonghai Zhang ${ }^{\mathrm{a}, *}$, Jinjia Wei ${ }^{\mathrm{a}, \mathrm{d}, *}$, \\ Yang Yang ${ }^{\mathrm{e}}$, Qian $\mathrm{Cao}^{\mathrm{e}}$ \\ a School of Chemical Engineering and Technology, Xi'an Jiaotong University, Xi'an 710049, China \\ ${ }^{\mathrm{b}}$ CAS Key Laboratory of Microgravity, Institute of Mechanics, Chinese Academy of Sciences, Beijing 100190, China \\ 'School of Engineering Science, University of Chinese Academy of Sciences, 19A Yuquan Rd, Beijing 100049, China \\ d State Key Laboratory of Multiphase Flow in Power Engineering, Xi'an Jiaotong University, Xi'an 710049, China \\ e Technology and Engineering Center for Space Utilization, Chinese Academy of Sciences, Beijing 100094, China
}

\section{A R T I C L E I N F O}

\section{Article history:}

Received 4 June 2019

Revised 9 October 2019

Accepted 10 November 2019

Available online 11 November 2019

\section{Keywords:}

Flow boiling heat transfer

Critical heat flux

Microgravity

Approximating method

\begin{abstract}
A B S T R A C T
A method for approximating the critical heat flux (CHF) of subcooled flow boiling in microgravity by ground tests was proposed. The method suggests that the flow boiling CHF in microgravity is less than that in normal gravity at a heating surface orientation $(\varphi)$ of $135^{\circ}$ but is greater than that in normal gravity when $\varphi=315^{\circ}$ at the corresponding conditions. The method was validated by drop tower experiments, and good agreement was observed from the results of all five tested cases. The method provided a new way to find the CHF of subcooled flow boiling in microgravity by ground tests.
\end{abstract}

(C) 2019 Elsevier Ltd. All rights reserved.

\section{Introduction}

Flow boiling is widely used in thermal management systems. With the development of aerospace technology, the study of flow boiling heat transfer under microgravity is of great significance to the heat dissipation of electronic devices and the thermal management for space equipment (Konishi and Mudawar, 2015a). However, the difficulty in obtaining microgravity conditions leads to costly experiments. In addition, the ability to conduct flow boiling heat transfer experiments is restricted due to the complexity of the experimental system. Therefore, only a few experiments of flow boiling in microgravity have been reported (Celata, 2007; Zhao, 2010).

The gravity level has an obvious influence on the flow boiling heat transfer performance, including the heat transfer coefficient and the critical heat flux (CHF) due to the notable change of buoyancy. Different trends of the flow boiling heat transfer coefficient, including a slight enhancement (Luciani et al., 2008; Baltis et al., 2012; Zhang et al., 2018a), deterioration (Ma and Chung, 2001; Ohta, 1997) and no difference (Zhang et al., 2018b), have been observed in microgravity at low and moderate heat fluxes com-

\footnotetext{
* Corresponding authors. Wei).

E-mail addresses: zyh002@mail.xjtu.edu.cn (Y. Zhang), jjwei@mail.xjtu.edu.cn (J.
}

pared to the trends in normal gravity. CHF decreases have been observed in all relevant publications. In addition, compared to the heat transfer performance at the CHF, it is easier to obtain similar performances under different gravity conditions at low and moderate heat fluxes. With the increase of the inlet velocity, the effects of the gravity levels on the flow boiling heat transfer coefficient in the low and moderate heat flux regions were weakened, and almost no difference in the flow boiling heat transfer coefficient was observed (Ma and Chung, 2001; Ohta, 1997; Zhang et al., 2018b, 2005; Ohta, 2013; Konishi et al., 2015b). Although the increased inlet velocity weakens the influence of gravity on the CHF, a decrease in the CHF has always been observed under microgravity conditions, even in the cases of high inlet velocities (Ma and Chung, 2001; Zhang et al., 2018b, 2005; Konishi et al., 2015b). Therefore, investigations of the flow boiling CHF under microgravity conditions are of great significance for guiding the design and operation of thermal management systems in microgravity.

Because flow boiling experiments in microgravity are not convenient, obtaining the value of the flow boiling CHF in microgravity by simulated experimental tests conducted on the ground is a very convenient and economical approach. Changing the orientation of the heating surface can directly affect the buoyancy of the bubbles and thus, the flow boiling heat transfer performance. Therefore, this method is usually used to study the effects of gravity on flow boiling heat transfer (Kirk et al., 1995; Merte et al., 2002; 


\begin{tabular}{|c|c|}
\hline \multicolumn{2}{|c|}{ Nomenclature } \\
\hline $\mathrm{CHF}$ & critical heat flux $\left(\mathrm{W} / \mathrm{cm}^{2}\right)$ \\
\hline$F_{\mathrm{b}}$ & buoyancy $(\mathrm{N})$ \\
\hline$F_{\mathrm{cp}}$ & contact pressure force $(\mathrm{N})$ \\
\hline$F_{\mathrm{du}}$ & unsteady drag force $(\mathrm{N})$ \\
\hline$F_{\mathrm{h}}$ & hydrodynamic pressure force $(\mathrm{N})$ \\
\hline$F_{\mathrm{m}}$ & Marangoni force $(\mathrm{N})$ \\
\hline$F_{\mathrm{qs}}$ & quasi-steady drag force $(\mathrm{N})$ \\
\hline$F_{S}$ & surface tension $(\mathrm{N})$ \\
\hline$F_{\mathrm{sl}}$ & shear lift force $(\mathrm{N})$ \\
\hline$g$ & gravitational acceleration $\left(\mathrm{m} / \mathrm{s}^{2}\right)$ \\
\hline$H$ & height of channel (mm) \\
\hline$I$ & heating current $(\mathrm{A})$ \\
\hline$L$ & length of heater (mm) \\
\hline$P$ & pressure (atm) \\
\hline$q$ & heat flux $\left(\mathrm{W} / \mathrm{cm}^{2}\right)$ \\
\hline$Q_{\mathrm{fc}}$ & heat of forced convection (W) \\
\hline$Q_{\text {tc }}$ & heat of transient conduction (W) \\
\hline$t$ & time $(s)$ \\
\hline$T_{\mathrm{a}}$ & average wall temperature $\left({ }^{\circ} \mathrm{C}\right)$ \\
\hline$T_{\mathrm{f}}$ & liquid temperature $\left({ }^{\circ} \mathrm{C}\right)$ \\
\hline$T_{\text {sat }}$ & saturation temperature $\left({ }^{\circ} \mathrm{C}\right)$ \\
\hline$T_{\mathrm{W}}$ & wall temperature $\left({ }^{\circ} \mathrm{C}\right)$ \\
\hline$U$ & heating voltage (V) \\
\hline V & liquid flow velocity $(\mathrm{m} / \mathrm{s})$ \\
\hline$W$ & width of heating surface (mm) \\
\hline \multicolumn{2}{|c|}{ Greek symbol } \\
\hline$\varphi$ & orientation of heating surface $\left(^{\circ}\right)$ \\
\hline$\varphi_{\mathrm{i}}$ & Angle of bubble incline \\
\hline \multicolumn{2}{|c|}{ Subscripts } \\
\hline con & conduction loss \\
\hline V & volume flow rate \\
\hline $\min$ & minimum \\
\hline sat & saturated \\
\hline sub & subcooled \\
\hline$\mu g$ & microgravity \\
\hline
\end{tabular}

Bower and Klausner, 2006; Lv et al., 1998; Zhang et al., 2002). However, no feasible method for simulating the flow boiling CHF in microgravity has been reported in the literature. Based on the experimental study of flow boiling with different orientations of the heating surface, Kirk et al. suggested that if the flow velocity exceeds the threshold value, the effects of the orientation, and thereby gravity, on flow boiling heat transfer can be completely neglected. However, the threshold value of flow velocity must be determined by experiments in microgravity (Kirk et al., 1995). Merte et al. proposed that the flow boiling characteristics in microgravity might be approximated by downward horizontal flow boiling in earth gravity when the liquid velocities $(V)$ are in the range of $5-10 \mathrm{~cm} / \mathrm{s}$ based on the analysis of dimensionless numbers, including the two-phase Richardson number, the two-phase Weber number, and the Bond number (Merte et al., 2002). However, there are no experimental results to validate this criterion. Similarly, combining the analysis of the Jakob number and a dimensionless flow rate parameter, Bower and Klausner established a gravity dependent/independent regime map using the variation of the Nusselt number coefficient to distinguish the threshold of gravityindependent heat transfer (Bower and Klausner, 2006). However, this gravity-dependent/independent regime map is only effective for flow boiling heat transfer in the low and moderate heat flux regions, and the CHFs under different orientations of the heating surface still show obvious deviations under this condition. Lv et al. proposed an equivalent criterion for simulating flow boiling in microgravity by ground tests (Lv et al., 1998). They pointed out that the flow boiling heat transfer performance in microgravity can be approximated when the wall temperature distribution of points along the test section has no sudden change, and the difference of the heat transfer performance between downward vertical flow boiling and upward vertical flow boiling in normal gravity can be negligible. However, to meet the equivalence criterion, the experimental conditions are too rigorous; in particular, the flow velocity is too high for space equipment. Zhang et al. conducted a series of experiments with different inlet velocities under different orientations of the heating surface $\left(0-360^{\circ}\right.$ with the increments of $45^{\circ}$ ) in normal gravity and compared the results with their experimental results in microgravity. Then, they proposed that the critical inlet velocity at which the influence of gravity on the CHF can almost be neglected is $1.5 \mathrm{~m} / \mathrm{s}$ for single heated conditions (the ratio of the flow boiling CHF in microgravity to that in normal gravity, $q_{\mathrm{CHF}-\mu \mathrm{g}} / q_{\mathrm{CHF}-1} 1 \mathrm{~g}$, is larger than 0.9 ) (Zhang et al., 2002; Zhang et al., 2005). The flow velocity should normally be controlled within $1.0 \mathrm{~m} / \mathrm{s}$ from the perspective of economics and operational safety. Therefore, the critical inlet velocity is not practical for application under most conditions.

In summary, there are three shortcomings in simulating the CHF of flow boiling under microgravity conditions by ground tests in the literature: 1) not enough attention has been paid to the simulation of the CHF; 2) most criteria lack experimental validation; and 3) the proposed critical flow velocity for simulating the CHF of flow boiling in microgravity is too high for practical applications under most conditions. Therefore, it is very beneficial to provide a convenient and economical experimental method in earth gravity to approximate the CHF of flow boiling in microgravity with a wide range of practical applications in space equipment.

In this study, a method for approximating the CHF of subcooled flow boiling in microgravity by ground tests is proposed based on the analysis of bubble dynamics and data from the literature. The method was validated by the drop tower experiment, and was further explained by a modified heat flux partitioning model in subcooled flow boiling.

\section{The conjecture of the method}

There are two kinds of bubble dynamic behaviours in the flow boiling heat transfer: bubble sliding and bubble lift-off. The occurrence of these two behaviours leads to the formation of volumetric voids in the superheated liquid layer, thereby forming a quenching effect by the subcooled liquid and taking away a large amount of heat, as shown in Fig. 1 (Basu et al., 2005a, 2005b).

The existence of the buoyancy influences the bubble sliding and bubble lift-off behaviours and thus affects the value of the CHF. The results of Basu et al. indicated that bubble sliding and bubble lift-off have a significant impact on the CHF of flow boiling (Basu et al., 2005a, 2005b). By analysing the effects of bubble sliding and bubble lift-off on transient heat conduction in normal gravity and microgravity, it is possible to find suitable ground experimental conditions to approximate the CHF of subcooled flow boiling in microgravity.

The force analysis of a single bubble in subcooled flow boiling is shown schematically in Fig. 2, where $\varphi$ represents the orientation of the heating surface, and the naming scheme for $\varphi$ is illustrated in Fig. 3. The single bubble force-balance model in subcooled flow boiling (Klausner et al., 1993; Zhang et al., 2014) can be expressed as

$\sum F_{\mathrm{x}}=F_{\mathrm{sx}}+F_{\mathrm{qs}}+F_{\mathrm{dux}}+F_{\mathrm{bx}}$

$\sum F_{\mathrm{y}}=F_{\mathrm{sy}}+F_{\mathrm{duy}}+F_{\mathrm{sl}}+F_{\mathrm{by}}+F_{\mathrm{h}}+F_{\mathrm{cp}}+F_{\mathrm{m}}$ 


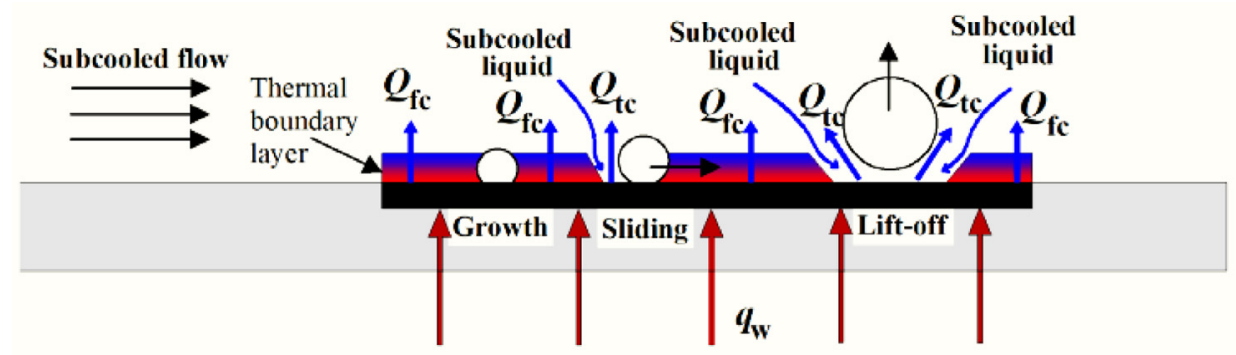

Fig. 1. The effects of bubble sliding and bubble lift-off on flow boiling heat transfer.

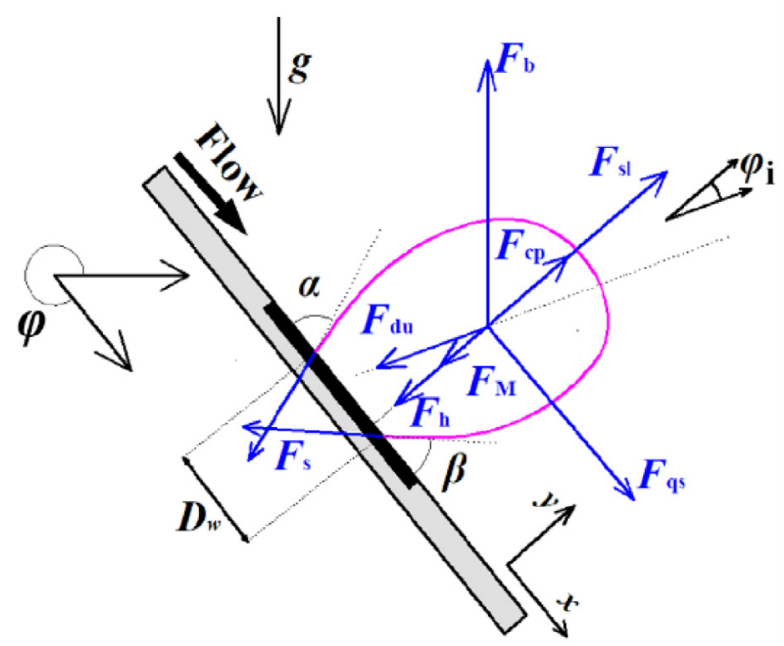

Fig. 2. Schematic diagram of force analysis for a single-bubble in subcooled flow boiling.

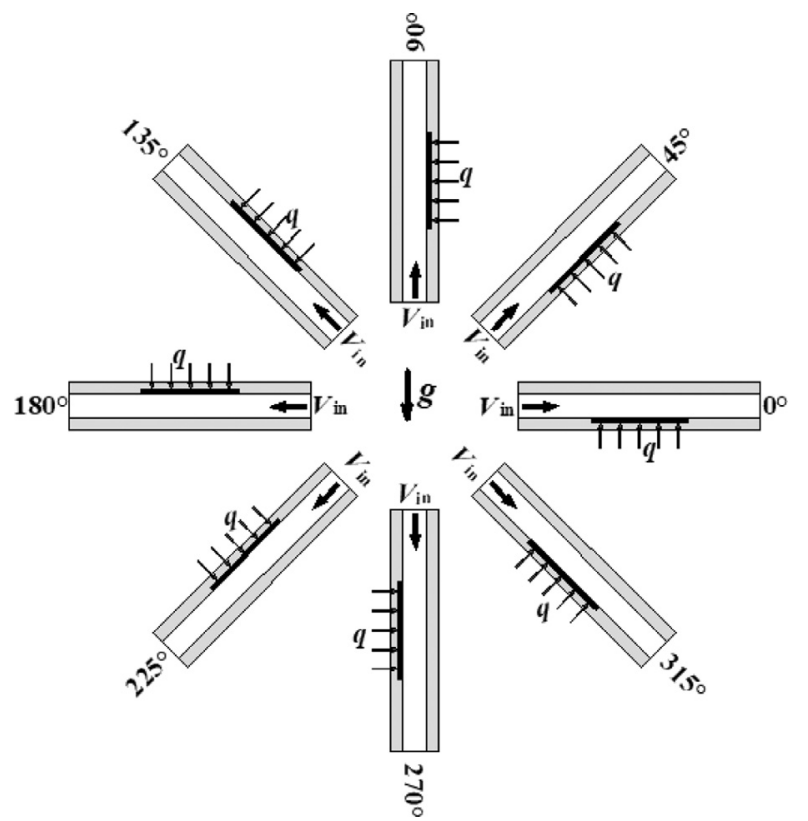

Fig. 3. Naming scheme for the orientation of heating surface.
Table 1

The effects of the orientation of heating surface on bubble behaviour.

\begin{tabular}{lllll}
\hline$\varphi$ & $F_{\mathrm{bx}}$ & Effect on bubble sliding & $F_{\mathrm{by}}$ & Effect bubble lift-off \\
\hline 0 & $=0$ & 0 & $>0$ & + \\
$\left(0^{\circ}, 90^{\circ}\right)$ & $>0$ & + & $>0$ & + \\
$90^{\circ}$ & $>0$ & + & $=0$ & 0 \\
$\left(90^{\circ}, 180^{\circ}\right)$ & $>0$ & + & $<0$ & - \\
$180^{\circ}$ & $=0$ & 0 & $<0$ & - \\
$\left(180^{\circ}, 270^{\circ}\right)$ & $<0$ & - & $<0$ & - \\
$270^{\circ}$ & $<0$ & - & $=0$ & 0 \\
$\left(270^{\circ}, 360^{\circ}\right)$ & $<0$ & - & $>0$ & + \\
\hline
\end{tabular}

where $F_{\mathrm{s}}, F_{\mathrm{qs}}, F_{\mathrm{du}}, F_{\mathrm{b}}, F_{\mathrm{sl}}, F_{\mathrm{h}}, F_{\mathrm{cp}}$, and $F_{\mathrm{m}}$ represent the surface tension, quasi-steady drag force, unsteady drag force, buoyancy, shear lift force, hydrodynamic pressure force, contact pressure force, and Marangoni force, respectively. The bubble slides on the heating surface when $\Sigma F_{\mathrm{x}}>0$ and $\Sigma F_{\mathrm{y}}<0$. While $\Sigma F_{\mathrm{y}}>0$, bubble lift-off occurs on the heating surface.

The components of the buoyancy $F_{\mathrm{b}}$ along the bubble sliding direction $F_{\mathrm{bx}}$ and the bubble lift-off direction $F_{\mathrm{by}}$ under the orientation of $\varphi$ are given by

$F_{\mathrm{bx}}=F_{\mathrm{b}} \cos \varphi$

$F_{\mathrm{by}}=F_{\mathrm{b}} \sin \varphi$

Then the effects of the orientation on the bubble behaviour can be obtained based on Eqs. (1)-(4), as shown in Table 1, where "+", "-" and " 0 " in the third and fifth columns indicate that the buoyancy has advantageous, disadvantageous and no effects on bubble sliding/lift-off. When the gravitational acceleration $g \rightarrow 0$, $F_{\mathrm{bx}}=F_{\mathrm{by}}=0$, and the buoyancy has no effect on bubble sliding and bubble lift-off in microgravity. In fact, it is impossible to obtain the same flow boiling phenomenon as the microgravity condition in normal gravity conditions because the effects of buoyancy cannot be eliminated in normal gravity. What we can do is find the condition(s) in which the effects of bubble sliding on flow boiling are opposite to those of bubble lift-off and then obtain the same value of the CHF in microgravity by the ground tests. When $90^{\circ}<\varphi<180^{\circ}$, buoyancy is beneficial to bubble sliding, but it is an obstruction to bubble lift-off. Then, the enhancement of flow boiling heat transfer due to the strengthened bubble sliding effect and the deterioration of flow boiling heat transfer due to the weakened bubble lift-off effect can be partially offset. Hence, for this case, it is possible to find an orientation in the range of $\left(90^{\circ}, 180^{\circ}\right)$ for which the value in normal gravity is close to that in microgravity for the same conditions. Similarly, when $270^{\circ}<\varphi<360^{\circ}$, buoyancy is good for bubble detachment, but it is not conducive to bubble sliding in normal gravity. The effects of bubble sliding on flow boiling heat transfer are opposite to those of bubble lift-off when the orientation of the heater is in the range of $\left(270^{\circ}, 360^{\circ}\right)$. Therefore, it is also possible to find an orientation in this range to 


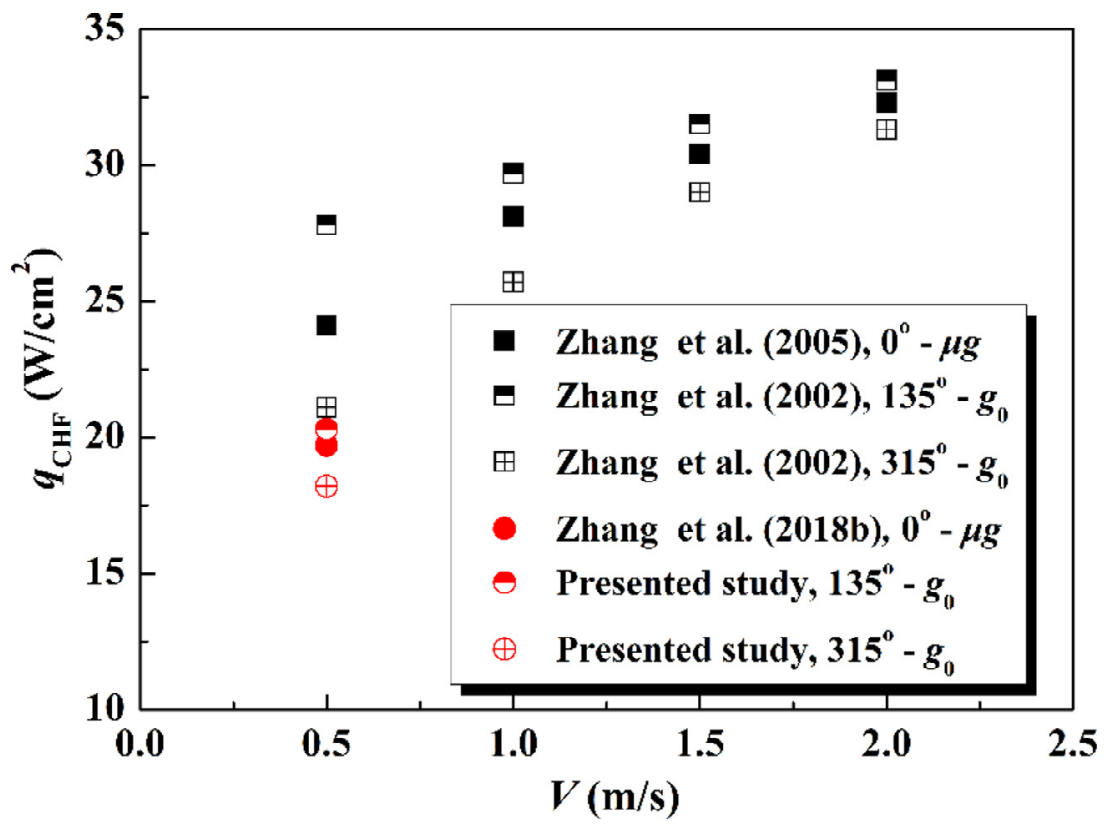

Fig. 4. The comparison of CHF data in microgravity and in normal gravity with the orientations of $135^{\circ}$ and $315^{\circ}$

obtain the same value as that in microgravity for the corresponding conditions. However, for other cases, the effects of buoyancy under different gravity levels on flow boiling heat transfer cannot be equal to each other. Then, it is possible to achieve the flow boiling $\mathrm{CHF}$ on the ground that approximates that in microgravity when $90^{\circ}<\varphi<180^{\circ}$ and $270^{\circ}<\varphi<360^{\circ}$

Usually, from the perspective of the feasibility and convenience of the experiments and to obtain similar buoyancy effects on the bubble dynamics $\left(\left|F_{\mathrm{bx}}\right|=\left|F_{\text {by }}\right|\right)$, an increment of $45^{\circ}$ in the orientation was adopted to investigate the effects of the heating surface orientation on flow boiling heat transfer. Therefore, the CHF results for $135^{\circ}$ (the median of $90^{\circ}$ and $180^{\circ}$ ) and $315^{\circ}$ (the median of $270^{\circ}$ and $360^{\circ}$ ) in normal gravity and the CHF data for $0^{\circ}$ in microgravity were used for comparison. Zhang et al. (Zhang et al., 2002, 2005) and Konishi et al. (Konishi et al., 2015b, 2015c) systematically studied the effects of the orientation and the gravity levels on the flow boiling CHF. However, the results of Konishi et al. were obtained from flow boiling experiments in a rectangular channel with opposite double-side heaters. The bubble behaviour under two opposite double-side heating is much more complex than that of single-side heating due to the merging of vapour bubbles generated by the downstream double-side heaters. Therefore, the results of Konishi et al. (2015b) and Konishi et al. (2015c) were not compared in this study. Further, data on the flow boiling CHF with different orientations in normal gravity under the corresponding conditions were tested in the present study (Zhang et al., 2018b).

The CHF data from the literature for $0^{\circ}$ in microgravity and in normal gravity with different orientations are shown in Fig. 4. It can be observed from Fig. 4 that the CHF with an orientation of $315^{\circ}\left(q_{\mathrm{CHF}-315^{\circ}}\right)$ is less than that of $135^{\circ}\left(q_{\mathrm{CHF}-135^{\circ}}\right)$ under the corresponding conditions. In addition, the CHF for $0^{\circ}$ for each case in microgravity $\left(q_{\mathrm{CHF}-\mu \mathrm{g}}\right)$ is in the range of $q_{\mathrm{CHF}-315^{\circ}}$ and $q_{\mathrm{CHF}-135^{\circ}}$ In other words, it can be assumed that the influence of buoyancy on the flow boiling CHF under microgravity when $\varphi=0^{\circ}$ is in the range of that on the flow boiling CHF when $\varphi=315^{\circ}$ and that on the flow boiling CHF when $\varphi=135^{\circ}$ Therefore, the CHF of subcooled flow boiling can be approximated in microgravity using the range of $q_{\mathrm{CHF}-315^{\circ}}$ and $q_{\mathrm{CHF}-135^{\circ}}$ in normal gravity under the corresponding conditions.

\section{Experimental validation}

\subsection{Experimental apparatus}

To verify the feasibility and correctness of the method, a series of subcooled flow boiling CHF data of FC-72 in microgravity were obtained through drop tower experiments in Beijing.

The drop tower experimental setup is similar to that reported in our previous studies (Zhang et al., 2018a, 2018b), as shown in Fig. 5. The test system consists of a fluid circulating system (including a pump, a potentiometer, a valve, pipelines, a rectangular channel, a tank, and a rubber bag), a testing section (including a DC power source and the heated surface), a data acquisition and visualization system (including thermocouples, a hall sensor, a data acquisition system, two standard resistances, two light sources and a high speed camera), and a fluid temperature controlling system (including an auxiliary heater, a condenser, and a temperature controller).

To facilitate the adjustment of the heated surface, silicone tubes were used as the pipelines of the experimental system. The rubber bag was fixed on the top of the tank and used to maintain the experimental pressure at $1 \mathrm{~atm}$. The test section with a size of $545 \times 80 \times 43 \mathrm{~mm}^{3}$ was made of transparent polycarbonate for visualization. A high-speed camera with a recording speed of 1000 fps was fixed on the top side of the heated surface. Two halogen bulbs were fixed on the two opposite sides of the high-speed camera at an angle of $45^{\circ}$ The working fluid is FC-72 ( $T_{\mathrm{sat}}=329 \mathrm{~K}$ at 1 atm), and the subcooling of the working fluid is $\left(\Delta T_{\text {sub }}\right) 15 \pm 0.5 \mathrm{~K}$.

As shown in Fig. 6, P-doped smooth silicon chips with a thickness of $0.5 \mathrm{~mm}$ and a width of $10 \mathrm{~mm}$ were used as heating surfaces. The resistivity of the silicon chip is $1-3 \Omega \cdot \mathrm{cm}$. Two copper wires were soldered on the two opposite ends of the silicon chips using the ultrasonic bonding method. The heating surface was Joule heated by a program-controlled DC power source, and flow boiling heat transfer occurred in a rectangular channel with a width of $12 \mathrm{~mm}$. To decrease the heat loss, the heating surface was bonded to a plexiglass plate and then packaged in a plexiglass base with heat insulation glue with a thickness of $1.5 \mathrm{~mm}$. The thermocouples were pasted on the bottom side of the heat- 


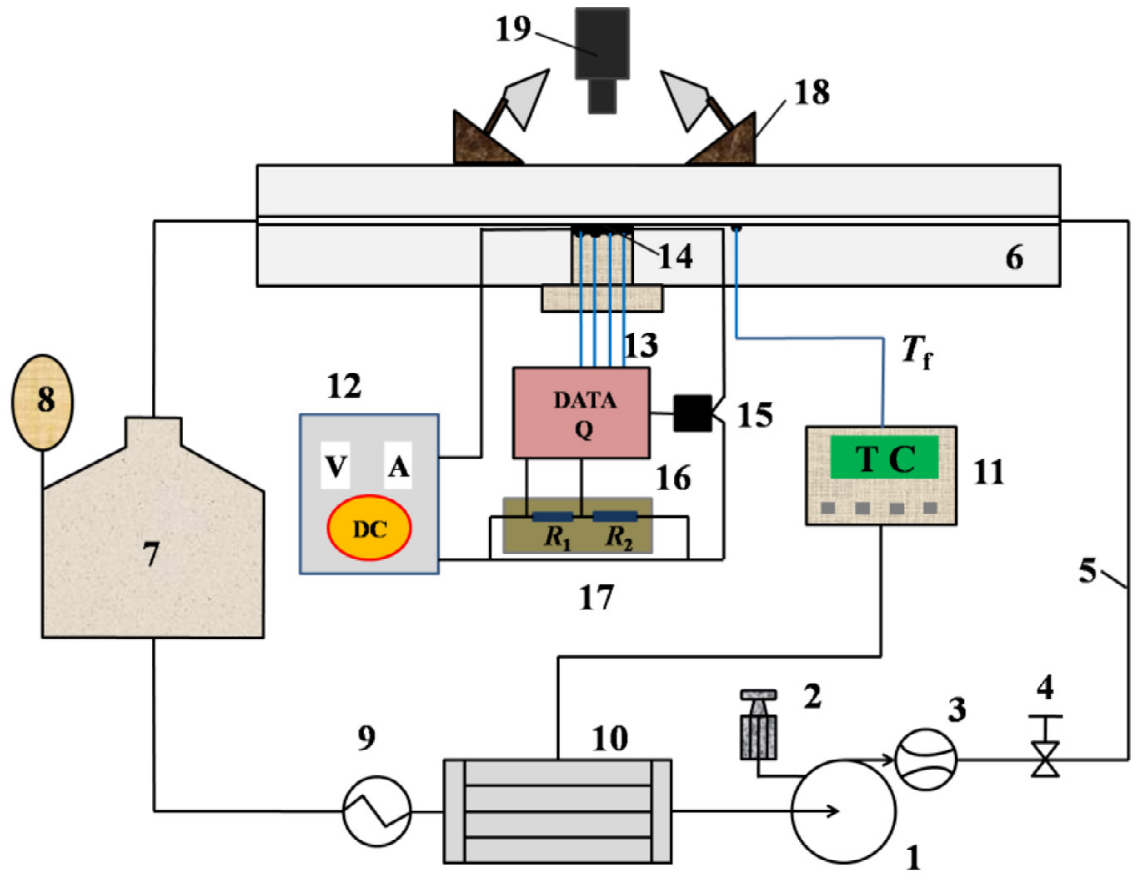

1. Pump 2. Potentiometer 3. Turbine flowmeter 4. Valve 5. Pipeline 6. Test section 7. Tank 8. Rubber bag 9. Auxiliary heater 10. Condenser 11. Temperature controller 12. DC power 13. Thermocouples 14. Heated surface 15. Hall sensor 16. Data acquisition 17. Standard resistance 18. Light source 19. High speed camera

Fig. 5. Schematic diagram of the experimental setup.

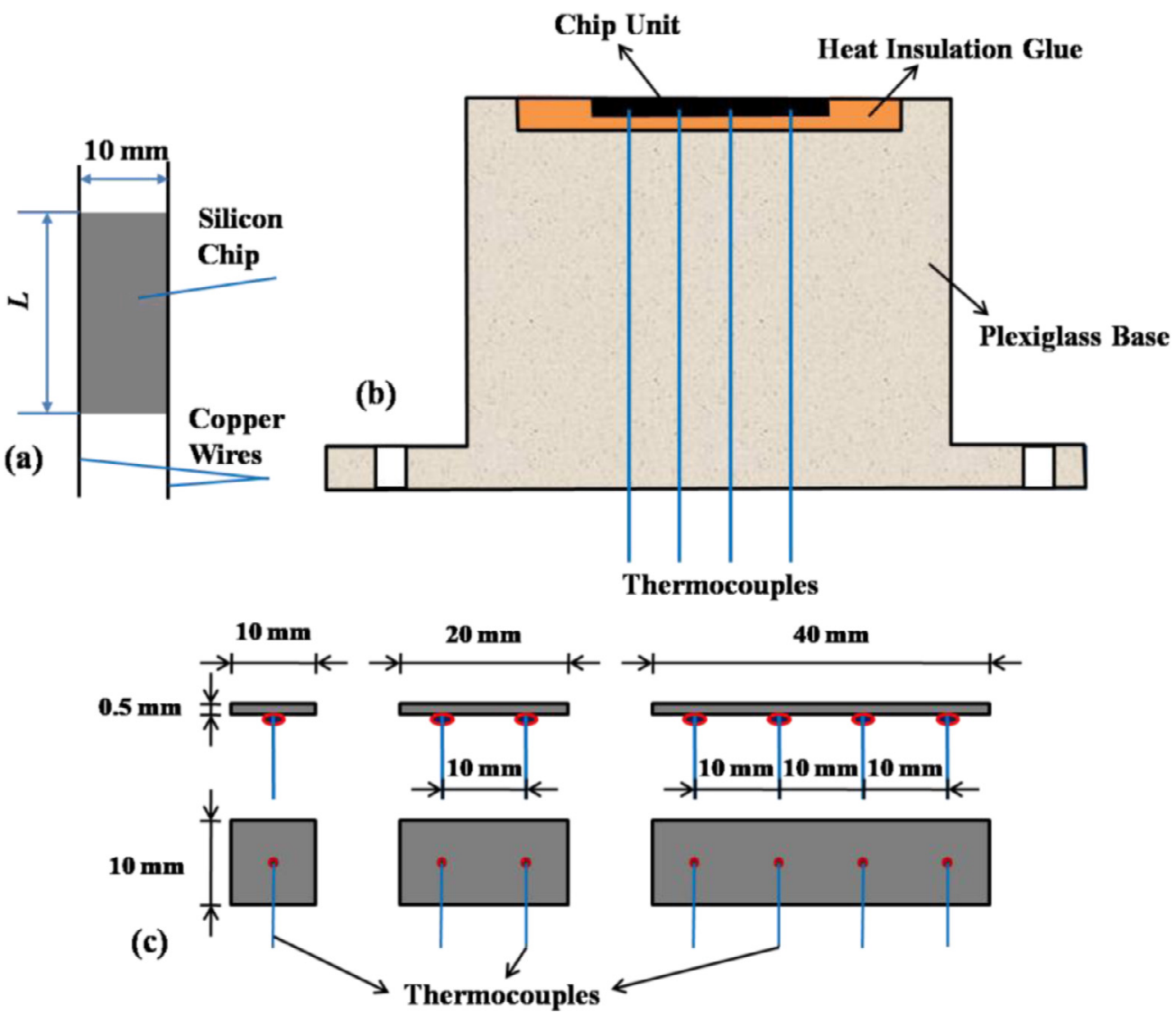

Fig. 6. Schematic diagram of the test section: (a) Test chip soldering, (b) Chip heating module and (c) Chip unit. 
Table 2

\begin{tabular}{|c|c|c|c|c|c|c|}
\hline Case number & $L(\mathrm{~mm})$ & $V(\mathrm{~m} / \mathrm{s})$ & $H(\mathrm{~mm})$ & $\varphi\left({ }^{\circ}\right)$ & $q_{\mathrm{CHF}}\left(\mathrm{W} / \mathrm{cm}^{2}\right)$ & $q_{\mathrm{CHF}} / q_{\mathrm{CHF} 0^{\circ}}$ \\
\hline \multirow[t]{3}{*}{ L40V05H3 } & 40 & 0.5 & 3 & 0 & 23.4 & $100 \%$ \\
\hline & & & & 135 & 20.4 & $87.2 \%$ \\
\hline & & & & 315 & 18.3 & $78.2 \%$ \\
\hline \multirow[t]{3}{*}{ L20V05H3 } & 20 & 0.5 & 3 & 0 & 24.4 & $100 \%$ \\
\hline & & & & 135 & 23.0 & $94.3 \%$ \\
\hline & & & & 315 & 20.8 & $85.2 \%$ \\
\hline \multirow[t]{3}{*}{ L10V05H3 } & 10 & 0.5 & 3 & 0 & 27.4 & $100 \%$ \\
\hline & & & & 135 & 26.0 & $95.0 \%$ \\
\hline & & & & 315 & 23.8 & $86.9 \%$ \\
\hline \multirow[t]{3}{*}{ L40V10H3 } & 40 & 1.0 & 3 & 0 & 26.8 & $100 \%$ \\
\hline & & & & 135 & 25.5 & $95.1 \%$ \\
\hline & & & & 315 & 23.6 & $88.1 \%$ \\
\hline \multirow[t]{3}{*}{ L40V05H5 } & 40 & 0.5 & 5 & 0 & 24.8 & $100 \%$ \\
\hline & & & & 135 & 22.1 & $89.1 \%$ \\
\hline & & & & 315 & 20.3 & $81.9 \%$ \\
\hline
\end{tabular}

ing surface with a thermally conductive adhesive at a distance of $10 \mathrm{~mm}$.

\subsection{Experimental procedures}

Due to experimental resource limitations, only 9 drop tower tests were conducted in this study. The critical flow velocities reported in the literature, i.e., $1.5 \mathrm{~m} / \mathrm{s}$ as reported by Zhang et al. (2005), are very high for the application of the thermal management system of space equipment. The range of flow velocities in the present study, $0.5-1.0 \mathrm{~m} / \mathrm{s}$, requires much less energy consumption by the system and is more suitable for the application to space equipment (Chiaramonte and Joshi, 2004; Zhang et al., 2005). Furthermore, the results of Zhang et al. (2005) indicated that this approximation method can also be used under the flow velocities of $0.5-2 \mathrm{~m} / \mathrm{s}$. Therefore, the flow velocity is not the main variate of the present study.

Considering the influences of the heater length $(L)$, flow velocity $(V)$ and channel height $(H)$ on the subcooled flow boiling CHF, five cases (L40V05H3: $L==40 \mathrm{~mm}, V==0.5 \mathrm{~m} / \mathrm{s}, H==3 \mathrm{~mm}$; L20V05H3: $L==20 \mathrm{~mm}, \quad V==0.5 \mathrm{~m} / \mathrm{s}, \quad H==3 \mathrm{~mm}$; L10V05H3: $L==10 \mathrm{~mm}, V==0.5 \mathrm{~m} / \mathrm{s}, \quad H==3 \mathrm{~mm} ; L 40 V 10 H 3: L==40 \mathrm{~mm}$, $V==1.0 \mathrm{~m} / \mathrm{s}, \quad H==3 \mathrm{~mm}$; L40V05H5: $L==40 \mathrm{~mm}, V==0.5 \mathrm{~m} / \mathrm{s}$, $H==5 \mathrm{~mm}$ ) of experiments were conducted to validate the method.

Before the drop tower experiments, the CHF values of three orientations $(\varphi)$ of the heating surface $\left(0^{\circ}, 135^{\circ}\right.$, and $\left.315^{\circ}\right)$ for each case were tested in normal gravity. Only the high heat flux region of the boiling curve that approaches the CHF was measured in the present study. To obtain the CHFs in normal gravity, the increments of heat flux were less than $0.3 \mathrm{~W} / \mathrm{cm}^{2}$. For each heat flux, the wall temperatures were monitored carefully to prevent the heated surface from burning up. When the CHF reaches a certain value, the wall temperatures increases dramatically, and the power is shut down in the meantime. The experimental conditions and results in normal gravity are listed in Table 2 . It can be found from Table 2 that $q_{\mathrm{CHF}-315^{\circ}}$ is always less than $q_{\mathrm{CHF}-135^{\circ}}$ under the corresponding conditions, which is similar to the results of single side heating in a rectangular channel, as reported in Zhang et al. (2002).

After measuring the CHFs of these three orientations, the operating conditions of the drop tower experiments can be obtained. Because the microgravity environment last for only $3.6 \mathrm{~s}$, we can only obtain the results of one heat flux for each drop tower experiment. Therefore, instead of a precise value, only the range of heat flux values that contains the CHF in microgravity can be obtained (Zhang et al., 2018a, 2018b). On the premise that this hypothesis is true, the CHF in microgravity will be in the range of $q_{\mathrm{CHF}-315^{\circ}}$ to $q_{\mathrm{CHF}-135^{\circ}}$ for each case. Therefore, the range of heat fluxes of the drop tower experiments are within the range of $q_{\mathrm{CHF}-315^{\circ}}$ to $q_{\mathrm{CHF}-135^{\circ}}$ for each case. Therefore, to ensure the success of every drop tower experiment and to avoid the burning up of the heating surface, the drop tower test with lower heat flux which is $q_{\mathrm{CHF}-315^{\circ}}$, was conducted firstly in normal gravity for each case. For instance, as with case L20V05H3, the set value of the heat flux for the first drop tower test was $20.8 \mathrm{~W} / \mathrm{cm}^{2}$. Subcooling was maintained at $15 \pm 0.5 \mathrm{~K}$ before $\mathrm{DC}$ power was applied. Next, the heating surface was heated under a constant input voltage to initiate boiling on the heater in terrestrial gravity before the release of the drop capsule for approximately $2.5 \mathrm{~min}$ until the flow boiling reached a steady state. Then, the drop capsule was released, and the highspeed camera was triggered to record. The pre-triggered time of the high-speed camera was set as $0.205 \mathrm{~s}$. Therefore, the bubble behaviours of the heated surface before and after the release of the drop capsule were recorded for each drop tower test. According to the flow boiling heat transfer performance at the lower heat flux of each case, the set value for the second run of the drop tower test for each case can be decided. Finally, the heat transfer performance at the higher heat flux of each can be tested by repeating the procedures mentioned above. More details on the experimental setup and the test procedures can be found in our previous articles (Zhang et al., 2018a, 2018b).

The heating voltage $(U)$ and heating current $(I)$ signals recorded by the data acquisition system were converted by two standard resistances and the hall sensor, respectively. The measured flow boiling heat flux of $q$ can be calculated as follows:

$q=\frac{U \cdot I}{L \cdot W}$

where $L$ and $W$ represent the length and width of the heating surface, respectively. The uncertainty of the measured heat flux can be calculated as

$$
\frac{\Delta q}{q}=\sqrt{\left(\frac{\Delta U}{U}\right)^{2}+\left(\frac{\Delta I}{I}\right)^{2}+\left(\frac{\Delta L}{L}\right)^{2}+\left(\frac{\Delta W}{W}\right)^{2}}
$$

In this study, only the data approaching the CHF were recorded (the minimum heat flux in this study is $18.2 \mathrm{~W} / \mathrm{cm}^{2}$ ). The measurement uncertainties for $\Delta U / U, \Delta I / I, \Delta L / L$, and $\Delta W / W$ are $0.1 \%$, $0.014 \%, 0.5 \%$ and $0.5 \%$, respectively. Therefore, the uncertainty of the measured flow boiling heat flux is $0.7 \%$. Considering the heat conduction loss through the substrate of the heating surface $\left(\Delta q_{\mathrm{con}} / q\right)$ and the effects of the fluctuation of the volume flow rate on the heat flux $\left(\Delta q_{\mathrm{V}} / q\right)$, the uncertainty of the total heat flux is calculated as

$$
\frac{\Delta q_{\mathrm{tot}}}{q}=\frac{\Delta q}{q}+\frac{\Delta q_{\mathrm{con}}}{q}+\frac{\Delta q_{\mathrm{V}}}{q}
$$



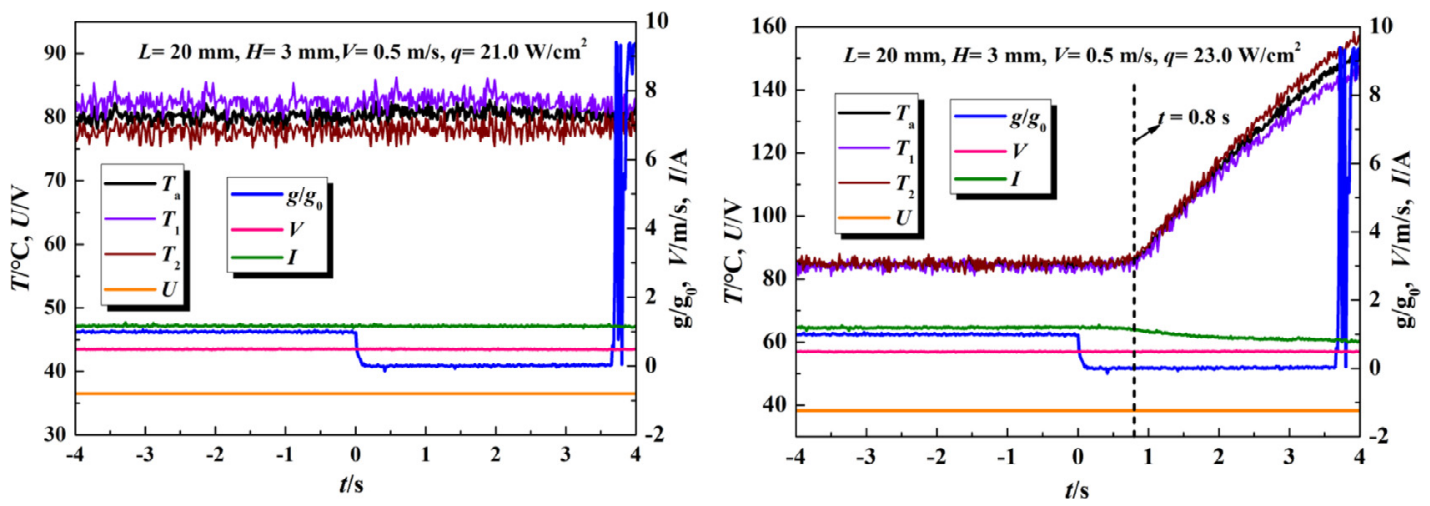

Fig. 7. Wall temperatures, heating voltage, heating current, and flow velocity in different gravity conditions for L20V05H3.

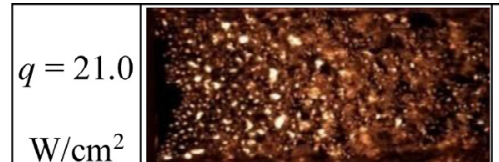

(a) $t=-0.1 \mathrm{~s}$

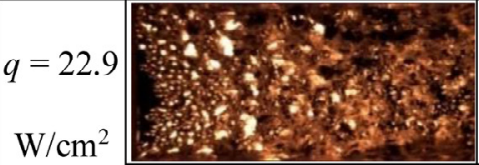

(a) $t=-0.1 \mathrm{~s}$

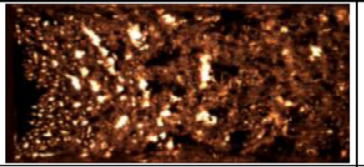

(b) $t=0.7 \mathrm{~s}$

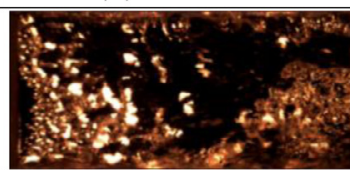

(b) $t=0.7 \mathrm{~s}$

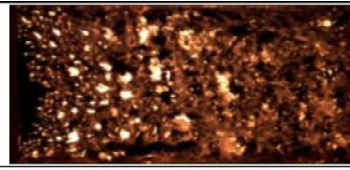

(c) $t=2.0 \mathrm{~s}$

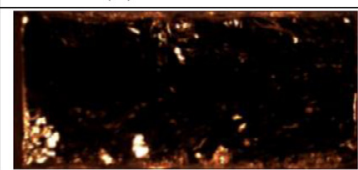

(c) $t=1.0 \mathrm{~s}$

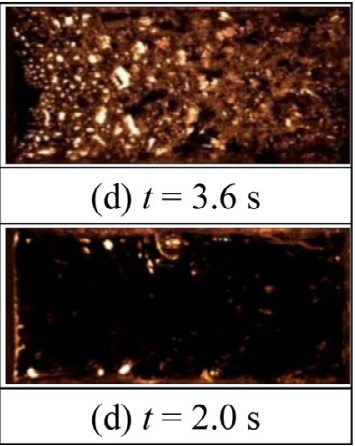

Fig. 8. Comparison of bubble behaviour in different gravity conditions for L20V05H3.

The thermal conductivity values of the plexiglass base and the heat insulation glue are approximately $0.2 \mathrm{~W} / \mathrm{m} \cdot \mathrm{K}$ and $0.15 \mathrm{~W} / \mathrm{m} \cdot \mathrm{K}$, respectively. According to the one-dimensional Fourier law, the heat loss through the substrate of the heating surface is estimated to be less than $1.5 \%$. The maximum uncertainty caused by the fluctuation of the volume flow rate $\Delta q_{\mathrm{V}} / q$ is approximately $1.1 \%$. Therefore, the uncertainty of the total heat flux is less than $2.0 \%$.

\subsection{Experimental results}

Due to experimental resource limitations, only 9 drop tower tests were conducted in this study, and each test was only conducted one time. The gravity level in microgravity $(\mu g)$ is approximately $10^{-2}$ to $10^{-3} \mathrm{~g}$, and $g$ is the gravitational acceleration on the ground. The free-falling period of microgravity during each drop tower test is $3.6 \mathrm{~s}$.

The flow boiling heat transfer performances of L20V05H3 for different gravity levels are shown in Fig. 7 and Fig. 8, where the time at which the microgravity condition began was set to $0 \mathrm{~s}$, and the flow boiling is in normal gravity when $t<0$ and in microgravity when $t>0$.

As for $q=21.0 \mathrm{~W} / \mathrm{cm}^{2}$, as shown in Fig. 7 , the wall temperatures ( $T_{1}$ and $T_{2}$ in Fig. 7(a) are the wall temperatures measured by the two thermocouples, and $T_{\mathrm{a}}$ represents the average value of $T_{1}$ and $T_{2}$ ) and the heating current are found to remain steady under different gravity levels. In addition, it can be observed from Fig. 8 that the heating surface is covered by a large number of bubbles in normal gravity $(t=-0.1 \mathrm{~s})$. Under the condition of microgravity $(t=0-3.6 \mathrm{~s})$, the coalescence behaviour of the bubbles increases slightly, which results in the occurrence of large \1apour patches downstream of the heating surface. Therefore, the difference of the bubble behaviour between the microgravity condition and the normal gravity condition is very small except for the slight serious bubble coalescence in microgravity. Zhang et al. reported that for flow boiling on a smooth surface with a length of $40 \mathrm{~mm}$, there is almost no deviation in flow boiling heat transfer and bubble behaviour except for the CHF (Zhang et al., 2018a). Therefore, it can be concluded that the flow boiling is still in the stable state and the CHF has not occurred at $q=21.0 \mathrm{~W} / \mathrm{cm}^{2}$ in microgravity.

At $q=23.0 \mathrm{~W} / \mathrm{cm}^{2}$, the wall temperatures increase sharply when $t=0.8 \mathrm{~s}$ (as shown in Fig. 7). Because the heating voltage $(U)$ was constant during the experiments and the material of the heating surface is P-doped silicon, the resistance of the heating surface increases with the increase of the wall temperature. Therefore, the heating current $(I)$ decreases obviously as the wall temperatures increase. The bubbles are generated vigorously on the heating surface in normal gravity $(t=-0.1 \mathrm{~s})$, while a large $\backslash 1$ apour film was observed on the heating surface at $t=0.7 \mathrm{~s}$. When $t=2.0 \mathrm{~s}$, the heating surface was entirely covered by the $\backslash 1$ apour film. This phenomenon indicated that a very rapid transition from nucleate boiling to film boiling has occurred after entering the microgravity condition. Therefore, it can be inferred that the CHF has occurred at this heat flux. Then, the CHF in microgravity for this case can be inferred to be between $21.0 \mathrm{~W} / \mathrm{cm}^{2}$ and $23.0 \mathrm{~W} / \mathrm{cm}^{2}$.

Similarly, the range of the CHF for the other cases can be obtained. The test conditions and results of the CHF in microgravity are listed in Table 3. According to the results reported in our previous study (Zhang et al., 2018b), the CHF of the smooth surface for L40V05H3 is between 18.2 and $21.3 \mathrm{~W} / \mathrm{cm}^{2}$ in microgravity, and the CHF when $\varphi=0^{\circ}$ for this case in normal gravity is $23.4 \mathrm{~W} / \mathrm{cm}^{2}$, which is very close to the value reported in Zhang et al. (2018b) $\left(23.2 \mathrm{~W} / \mathrm{cm}^{2}\right)$. Furthermore, $q=18.2 \mathrm{~W} / \mathrm{cm}^{2}$ is very close to the $q_{\mathrm{CHF}-315^{\circ}}$ of L40V05H3. Therefore, the results of $q=18.2 \mathrm{~W} / \mathrm{cm}^{2}$ in Zhang et al. (2018b) were also used for the validation of this method. According to the results of Table 3 , the relationship of the CHF in normal gravity under $\varphi=135^{\circ}$ and $\varphi=315^{\circ}$ and the CHF in microgravity can be compared, as shown in Fig. 9. 
Table 3

The results of CHF in microgravity.

\begin{tabular}{lllll}
\hline Case number & $q\left(\mathrm{~W} / \mathrm{cm}^{2}\right)$ & $q / q_{\mathrm{CHF}-0^{\circ}}$ & Whether the CHF has occurred & $q_{\mathrm{CHF}-\mu \mathrm{g}} / q_{\mathrm{CHF}-0^{\circ}}$ \\
\hline L40V05H3 & 18.2 & $77.8 \%$ & No & $77.8 \%-83.8 \%$ \\
& 19.6 & $83.8 \%$ & Yes & \\
L20V05H3 & 21.0 & $86.1 \%$ & No & $86.1 \%-93.9 \%$ \\
& 22.9 & $93.9 \%$ & Yes & \\
L10V05H3 & 24.2 & $88.3 \%$ & No & $88.3 \%-95.0 \%$ \\
& 26.0 & $95.0 \%$ & Yes & \\
L40V10H3 & 23.7 & $88.1 \%$ & No & $88.1 \%-92.2 \%$ \\
& 24.7 & $92.2 \%$ & Yes & \\
L40V05H5 & 20.1 & $81.0 \%$ & No & \\
& 21.6 & $87.1 \%$ & Yes & \\
\hline
\end{tabular}

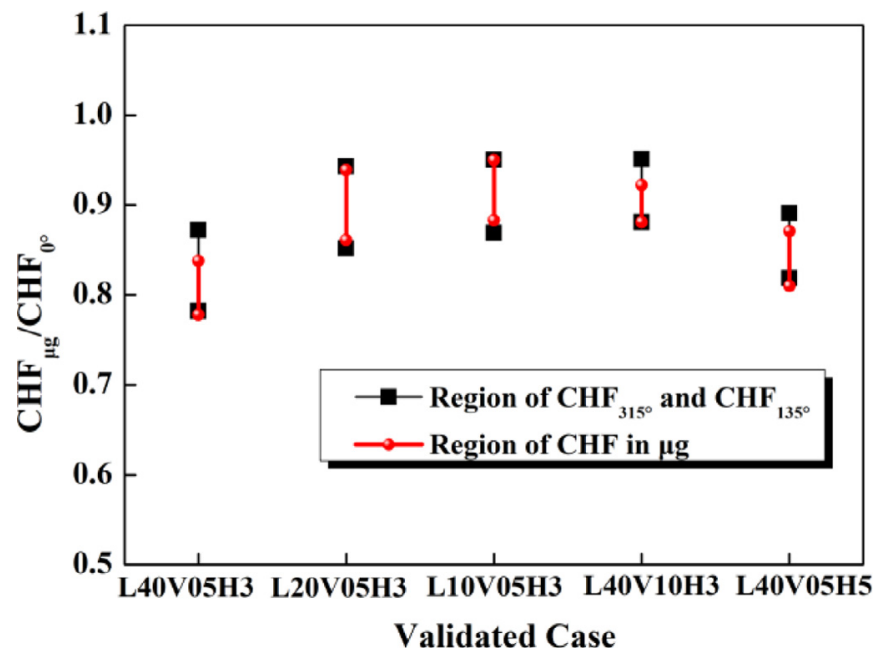

Fig. 9. Comparison of $\mathrm{CHF}$ regions at different gravity levels.

It can be found from Table 3 and Fig. 9 that the flow boiling CHF under microgravity conditions is in the range of $q_{\mathrm{CHF}-315^{\circ}}$ and $q_{\mathrm{CHF}-135^{\circ}}$ for each case. These results suggest that the subcooled flow boiling CHF in microgravity can be approximated by the range of $q_{\mathrm{CHF}-315^{\circ}}$ and $q_{\mathrm{CHF}-135^{\circ}}$ in normal gravity under the corresponding conditions. Therefore, the method for approximating the CHF of subcooled flow boiling in microgravity is feasible and valid for all the five cases. Furthermore, the maximum difference of the CHF between $135^{\circ}$ and $315^{\circ}$ is only $2.2 \mathrm{~W} / \mathrm{cm}^{2}$ (L20V05H3 and $\mathrm{L} 10 \mathrm{~V} 05 \mathrm{H} 3$ ), and the maximum deviation of the method for approximating the CHF under microgravity conditions in this study is only $9.1 \%$, which means that the method has the advantage of high precision when obtaining the CHF of subcooled flow boiling in microgravity.

\section{Conclusions}

A method for approximating the subcooled flow boiling CHF in microgravity by ground tests, in which the CHF in microgravity can be approximated by the range of $\mathrm{CHF}_{315^{\circ}}$ and $\mathrm{CHF}_{135^{\circ}}$ in normal gravity, was proposed. The method was validated by the drop tower experimental results. The experimental data covered in the present study are for single-side heated subcooled flow boiling with the following range of parameters: pressure $P=1 \mathrm{~atm}$; inlet velocity $V=0.5-1.0 \mathrm{~m} / \mathrm{s}$; length of heater $L=10-40 \mathrm{~mm}$; subcooling $\Delta T_{\text {sub }}=15 \mathrm{~K}$; and height of the channel $H=3-5 \mathrm{~mm}$. Good agreement was observed from the results of all five tested cases.

The study provides a new convenient, economical and precise method to find the subcooled flow boiling CHF in microgravity by ground tests.

\section{Declaration of Competing Interest}

None.

\section{Acknowledgments}

This work is supported by the project of Young Elite Scientists Sponsorship Program by CAST (2018QNRC001), Joint ESA-CMSA Project (TGMTYY00-RW-05-1.00), National Natural Science Foundation of China (No.51636006, No.51506169), Basic Research Project of Shenzhen Knowledge Innovation Program (JCYJ20180306170627132), the Fundamental Research Funds For the Central Universities (No.cxtd2017004, xjj2017085), and the Postdoctoral Research Project of Shaanxi Province (2016BSHEDZZ131).

\section{References}

Baltis, C., Celata, G.P., Cumo, M., Saraceno, L., Zummo, G., 2012. Gravity influence on heat transfer rate in flow boiling. Microgravity Sci. Technol. 24 (3), 203-213. doi:10.1007/s12217-012-9298-5.

Basu, N., Warrier, G.R., Dhir, V.K., 2005a. Wall heat flux partitioning during subcooled flow boiling: part 1-model development. J. Heat Transf. 127, 131-140. doi:10.1115/1.1842784.

Basu, N., Warrier, G.R., Dhir, V.K., 2005b. Wall heat flux partitioning during subcooled flow boiling: part II-model validation. J. Heat Transf. 127, 141-148. doi: $10.1115 / 1.1842785$.

Bower, J.S., Klausner, J.F., 2006. Gravity independent subcooled flow boiling heat transfer regime. Exp. Therm. Fluid Sci 31 (2), 141-149. doi:10.1016/j. expthermflusci.2006.03.024

Celata, G.P., 2007. Flow boiling heat transfer in microgravity: recent results. Microgravity Sci. Technol. 19 (3-4), 13-17. doi:10.1007/BF02915738.

Chiaramonte, F.P., Joshi, J.A., 2004. Workshop on critical issues in microgravity fluids, transport, and reaction processes in advanced human support technology-Final report. NASA TM-2004-212940.

Kirk, K.M., Merte, H., Keller, R., 1995. Low-velocity subcooled nucleate flow boiling at various orientations. J. Heat Transf. 117 (2), 380. doi:10.1115/1.2822533.

Klausner, J.F., Mei, R., Bernhard, D.M., Zeng, L.Z., 1993. Vapor bubble departure in forced convection boiling. Int. J. Heat Mass Transf. 36 (3), 651-662. doi:10.1016/ 0017-9310(93)80041-r.

Konishi, C., Lee, H., Mudawar, I., Hasan, M.M., Nahra, H.K., Hall, N.R., Wagner, J.D., May, R.L., Mackey, J.R., 2015b. Flow boiling in microgravity: part 1-Interfacial behavior and experimental heat transfer results. Int. J. Heat Mass Transf. 81, 705-720. doi:10.1016/j.ijheatmasstransfer.2014.10.049.

Konishi, C., Lee, H., Mudawar, I., Hasan, M.M., Nahra, H.K., Hall, N.R., Wagner, J.D., May, R.L., Mackey, J.R., 2015c. Flow boiling in microgravity: part 2-Critical heat flux interfacial behavior, experimental data, and model, configurations. Int. J. Heat Mass Transf. 81, 721-736. doi:10.1016/j.ijheatmasstransfer.2014.10.052.

Konishi, C., Mudawar, I., 2015a. Review of flow boiling and critical heat flux in microgravity. Int. J. Heat Mass Transf. 80, 469-493. doi:10.1016/j. ijheatmasstransfer.2014.09.017.

Luciani, S., Brutin, D., Niliot, C.L., Rahli, O., Tadrist, L., 2008. Flow boiling in minichannels under normal, hyper-, and microgravity: local heat transfer analysis using inverse methods. J. Heat Transf. 130, 101502. doi:10.1115 icnmm2007-30153.

Lv, C.D., Li, F.J., Wang, H.Q., Cheng, S.M., 1998. Analysis on modeling conditions of two-phase flow boiling heat transfer under microgravity. J. Huazhong Univ. Sci. Tech. 26 (4), 81-83. doi:10.13245/j.hust.1998.04.027.

Ma, Y., Chung, J.N., 2001. An experimental study of critical heat flux (CHF) in microgravity forced-convection boiling. Int. J. Multiph. Flow 27 (10), 1753-1767. doi:10.1016/s0301-9322(01)00031-3. 
Merte, H., Park, J., Shultz, W.W., Keller, R.B., 2002. Criteria for approximating certain microgravity flow boiling characteristics in earth gravity. Ann. N. Y. Acad. Sci. 974 (1), 481-503. doi:10.1111/j.1749-6632.2002.tb05926.x.

Ohta, H., 1997. Experiments on microgravity boiling heat transfer by using transparent heaters. Nucl. Eng. Des. 175, 167-180. doi:10.1016/s0029-5493(97)00172-6.

Ohta, H., Baba, S., 2013. Boiling experiments under microgravity conditions. Exp. Heat Transf. 26, 266-295. doi:10.1080/08916152.2012.736850, 2-3.

Zhang, H., Mudawar, I., Hasan, M.M., 2002. Experimental assessment of the effects of body force, surface tension force, and inertia on flow boiling CHF. Int. J. Heat Mass Transf. 45, 4079-4095. doi:10.1016/s0017-9310(02)00133-3.

Zhang, H., Mudawar, I., Hasan, M.M., 2005. Flow boiling CHF in microgravity. Int. J. Heat Mass Transf. 48 (15), 3107-3118. doi:10.1016/j.ijheatmasstransfer.2005.02. 015.
Zhang, Y.H., Liu, B., Zhao, J.F., Deng, Y.P., Wei, J.J., 2018a. Experimental study of subcooled flow boiling heat transfer on a smooth surface in short-term microgravity. Microgravity Sci. Technol. 30 (6), 793-805. doi:10.1007/s12217-018-9629-2.

Zhang, Y.H., Liu, B., Zhao, J.F., Deng, Y.P., Wei, J.J., 2018b. Experimental study of subcooled flow boiling heat transfer on micro-pin-finned surfaces in short-term microgravity. Exp. Therm. Fluid Sci. 97, 417-430. doi:10.1016/j.expthermflusci. 2018.05.003.

Zhang, Y.H., Wei, J.J., Xue, Y.F., Kong, X., Zhao, J.F., 2014. Bubble dynamics in nucleate pool boiling on micro-pin-finned surfaces in microgravity. Appl. Therm. Eng. 70 (1), 172-182. doi:10.1016/j.applthermaleng.2014.04.074.

Zhao, J.F., 2010. Two-phase flow and pool boiling heat transfer in microgravity. Int J. Multiph. Flow 36 (2), 135-143. doi:10.1016/j.ijmultiphaseflow.2009.09.001. 